\title{
Parametric Investigation of De-Sulfurization Process for Sour Gas; Introduction of Novel System
}

\author{
Somayyeh Fazeli ${ }^{1}$, Farshad Farahbod ${ }^{2, *}$ \\ ${ }^{1}$ Department of Chemical Engineering, Sirjan Branch, Islamic Azad University, Sirjan, Iran \\ ${ }^{2}$ Department of Chemical Engineering, Firoozabad Branch, Islamic Azad University, Firoozabad, Iran
}

\section{Email address:}

f.farahbod@iauf.ac.ir (F. Farahbod)

${ }^{*}$ Corresponding author

\section{To cite this article:}

Somayyeh Fazeli, Farshad Farahbod. Parametric Investigation of De-Sulfurization Process for Sour Gas; Introduction of Novel System. International Journal of Oil, Gas and Coal Engineering. Vol. 5, No. 1, 2017, pp. 1-4. doi: 10.11648/j.ogce.20170501.11

Received: January 7, 2017; Accepted: January 17, 2017; Published: February 27, 2017

\begin{abstract}
Many different processes are used to treat raw natural gas to pipeline quality. The sulfur is commonly present as an impurity in fossil fuels. Magnetic field is applied in a fluidized bed which contains nano activated carbon to investigate hydrogen sulfide elimination, in this paper. Sulfur removal in this way is presented experimentally and theoretically. The rate of mass transfer is introduced as function of gas temperature, amount of balls covered by nano carbon tubes, initial concentration of hydrogen sulfide, gas flow rate and also, magnetic field. The experimental data are presented and compared with the model results. The effect of hydrogen sulfide in the inlet sour gas on the mass flow rate in investigated in this paper. In addition, the effect of porosity percentage of catalytic bed on the hydrogen sulfide content of outlet gas is evaluated in this paper. The outlet concentration below $4 \mathrm{ppm}$ is acceptable result due to commercial rules. The experimental data are in higher values of hydrogen sulfide comparing with the ones from modeling data.
\end{abstract}

Keywords: Nano, Hydrogen Sulfide, Flow, Field, Temperature

\section{Introduction}

There are different types of sour gas. The sulfur element and related compounds approach sweet gas to the sour gas. The sulfur damages units and pipe lines, severally. In addition, the sulfur causes to the catalysts poisonings [1-5]. Burning fuels, the sulfur is released as sulfur dioxide - an air pollutant responsible for respiratory problems and acid rain [6-8]. Environmental regulations have increasingly restricted sulfur dioxide emissions, forcing fuel processors to remove the sulfur from both fuels and exhaust gases. The cost of removing sulfur from natural gas and petroleum in the United States was about $\$ 1.25$ billion in 2008. In natural gas, sulfur is present mainly as hydrogen sulfide gas $\left(\mathrm{H}_{2} \mathrm{~S}\right)$, while in crude oil it is present in sulfur-containing organic compounds which are converted into hydrocarbons and $\mathrm{H}_{2} \mathrm{~S}$ during the hydro desulphurization [9-13]. In both cases, corrosive, highly-toxic $\mathrm{H}_{2} \mathrm{~S}$ gas must be converted into elemental sulfur and removed for sale or safe disposal [14-16]. Formation fluids that contain Hydrogen Sulfide - By-product from anaerobic bacterial action on sulfur compounds present in the mud (i.e. Sodium Sulfite) - Thermal degradation of mud additives containing sulfur (i.e. Lignosulfonates) - Chemical reactions with tool joint lubricants containing sulfur [16-20].

$\mathrm{H}_{2} \mathrm{~S}$ is a weak acid that can go through the following 2 stages when dissolved in water or water based mud [21];

$$
\mathrm{H}_{2} \mathrm{~S} \leftrightarrow+\mathrm{H}+\mathrm{HS}-\text { - }
$$

both steps (1 and 2) can go back and forth depending on the $\mathrm{pH}$.

$$
\text { HS- }+ \text { OH- } \leftrightarrow-S+\mathrm{H}_{2} \mathrm{O}
$$

\section{Materials and Method}

Sour gasses which contain different amounts of hydrogen sulfide are reactor bed feed. Two gray 20 lit of volume pressurized vessel contain sour gas can be joint to the experimental line. However, both feed vessel can't be used simultaneously. Plexiglas vessel with inside diameter of $8 \mathrm{~cm}$ and height of $60 \mathrm{~cm}$ is the reactor vessel. $1 \mathrm{~cm}$ from bottom 
and $1 \mathrm{~cm}$ from the top of inside height of vessel is without packing contains distributor and holders. In $4 \mathrm{~cm}$ of efficient volume of vessel plastic balls with $2.5 \mathrm{~cm}$ in diameter which are covered by nano activated carbon tubes are used as the packing.

\subsection{Chemical Reaction}

Pre humidification is done to enhance the amount of adsorbed $\mathrm{H}_{2} \mathrm{~S}$ on nano balls. Nano carbon tubes are contacted with moist air $(\mathrm{RH}=100 \%)$ for $20 \mathrm{~min}$ before using in the reactor. This time is longer for current activated carbon but nano carbon is applied in this study and humidity adsorption occurs in shorter contact time. This step is an exothermic process. Humidity helps oxidation of $\mathrm{H}_{2} \mathrm{~S}$ and also increases the nano carbon capacity for $\mathrm{H}_{2} \mathrm{~S}$ adsorption.

\subsection{Mathematical Modeling}

For laminar flow, where only viscous drag forces come into play, (NRe, $\mathrm{p}<20$ ), experimental data may be correlated by means of the Kozeny-Carman equation, the Equation 3 [1]:

$$
f_{b}=\frac{150(1-\varepsilon)}{N_{\operatorname{Re}, p} \varphi_{s}}
$$

Note: According to chemical engineering hand book [5], the factor of 150 was originally given by Carman as 180 for the case of laminar flow. Ergun later suggested a better value was 150 when the particles are greater than about $150 \mu \mathrm{m}$ in diameter.

In addition, for highly turbulent flow where inertial forces predominate, NRe, p (>1000), experimental results may instead be correlated in terms of the Blake-Plummer equation, Equation 4 [7]:

$$
f_{b}=1.75
$$

\section{Results and Discussion}

Bed porosity, inlet gas temperature, inlet concentration of $\mathrm{H}_{2} \mathrm{~S}$, magnetic field which influences the mass transfer area, mass transfer coefficient and rate of reaction are considered here.

The amounts of hydrogen sulfide catch from branch line defined the process performance. Inlet sour gas contains 148 ppm $\mathrm{H} 2 \mathrm{~S}$, temperature of $30 \mathrm{C}$ is fed into the catalytic bed with $0.48 \mathrm{~m}^{3} / \mathrm{m}^{3}$ porosity and magnetic field occurred with current of $1 \mathrm{~A}$.

\subsection{The Effect of Bed Porosity on Sulfur Elimination}

Three different amounts of porosity are achieved by three numbers of balls, 4,5 and 6 balls. In this case higher porosity presents lower amount of nano carbon tube and also lower amount of mass transfer surface area. In the fluidized bed the channeling malfunction is not occurred and all packing's are moved with the gas velocity and gas is contacted to solid catalyst easily. There is not any unused surface area. So, the increase trend of $\mathrm{C}$ is predicted by increase in the amount of porosity. Outlet concentration below $4 \mathrm{ppm}$ is acceptable result due to commercial rules. Experimental data are in higher values of hydrogen sulfide comparing with ones from modeling data. Figure 1 shows the trend of outlet hydrogen sulfide concentration with bed porosity, $\mathrm{V}_{\mathrm{nb}} / \mathrm{V}$.

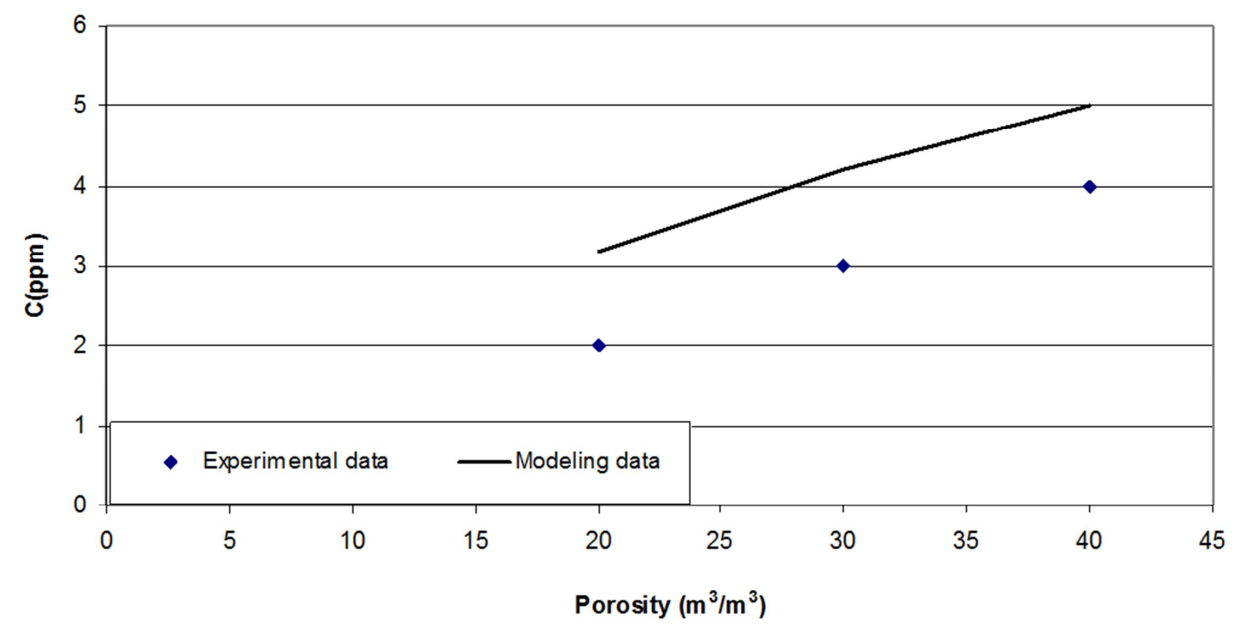

Figure 1. The effect of porosity on outlet hydrogen sulfide.

\subsection{The Effect of Initial Concentration and Gas Flow Rate}

Gas phase is not pure so gas, liquid and solid resistance should be considered in mass transfer rate. $\mathrm{H}_{2} \mathrm{~S}$ adsorption on catalyst surface is considered physically and chemically. Both mechanisms are dependent on film of water on the nano carbon tubes. The effect of gas flow rate on mass transfer rate and mass transfer coefficient is studied here. The increase in initial amount of hydrogen sulfide decreases the gas phase resistance and facilitates the total mass transfer rate. The increase in flow rate with the fixed surface area increases the gas velocity and turbulence of gas phase. This also increases the solubility of $\mathrm{H}_{2} \mathrm{~S}$ on water film. 


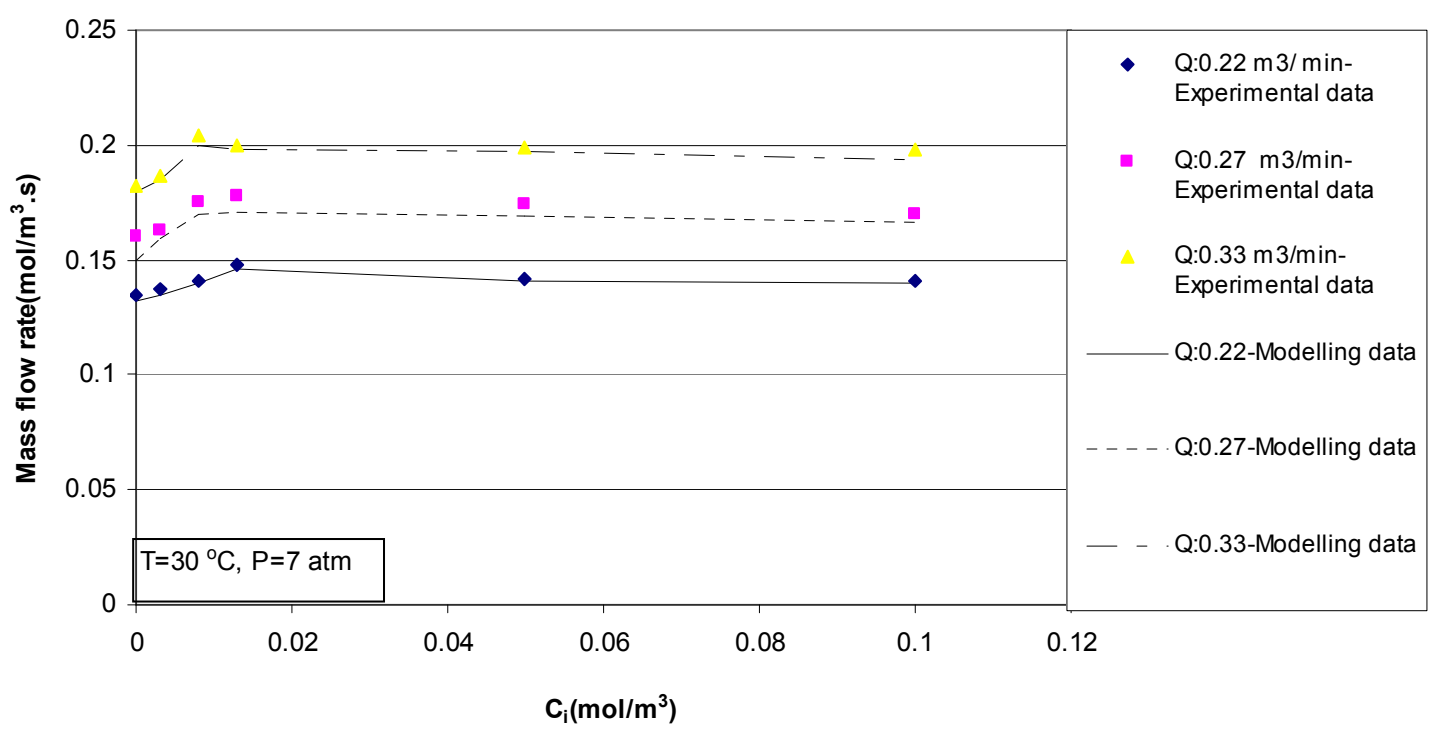

Figure 2. Mass flow rate versus inlet hydrogen sulfide and gas velocity.

Figure 2 shows the effect of gas flow rate and initial concentration of hydrogen sulfide on values of mass transfer flow rate. The increase in amount of gas flow rate increases the value of mass flow rate. This may indicate on the high adsorption capacity of nano carbon tubes and high surface area in fluidized bed. At $0.22 \mathrm{~m}^{3} / \mathrm{min}$ value of gas flow rate the increase in amount of initial hydrogen sulfur ( 0 to 0.013 $\mathrm{mol} / \mathrm{m}^{3}$ ) increases the flow rate initially and then the relatively decrease trend in flow rate is observed. This trend is similar for both 0.27 and 0.33 but the peak of graph happens in lower amount of initial hydrogen sulfide. This shows the limited value of carbon nano tube capacity. Also, the positive effect of turbulence on decreasing the gas phase resistance is observed. The higher value of driving force doesn't show the significant effect on increase of mass transfer rate when the capacity of nano carbon is limited. However, the theoretical values are predicted in lower ranges than values of experimental data. This difference may relate to calculation of mass transfer coefficient. The average mass transfer coefficient for gas phase is only considered in the relation while there is mass transfer coefficient for liquid film, actually.

\section{Conclusion}

Fluidized bed equipped with magnetic field which contains nano carbon tube is used to remove hydrogen sulfide from sour natural gas. Mass transfer rate and mass transfer coefficient is measured and calculated experimentally and theoretically. The rate of mass transfer is introduced as function of gas temperature, amount of balls covered by nano carbon tubes, initial concentration of hydrogen sulfide, gas flow rate and magnetic field. Results show the hydrogen sulfide in outlet stream increases with increasing the porosity. In addition, the obtained results show the exponential correlation can defined the relation between the friction factor and pressure drop. The mass flow rate versus initial concentration of hydrogen sulfide is evaluated in this study. The experimental results show the initial concentration can be affected on the mass flow rate at the beginning.

\section{References}

[1] G. J. McLachlan, D. Peel, Finite Mixture Models, Wiley Series in Probability and Statistics, A Wiley-Interscience Publication, 2000.

[2] P. D. Tennis, H. M. Jennings, A model for two types of calcium silicate hydrate in the microstructure of Portland cement pastes, Cem. Concr. Res. 30 (2000) 855-863.

[3] J. Goldstein, Scanning Electron Microscopy and X-ray Microanalysis, Springer, New York, 2008.

[4] M. Miller, Ch. Bobko, M. Vandamme, F.-J. Ulm, "Surface roughness criteria for cement paste nanoindentation", Cem. Concr. Res. 38 (4) (2011) 467-476.

[5] E. R. Buckle, H. F. W. Taylor, The hydration of tricalcium and $\beta$-dicalcium silicates in pastes under normal and steam curing conditions, J. Appl. Chem. 9 (1959) 163-172.

[6] H. F. W. Taylor, The steam curing of Portland cement products, in: H. F. W. Taylor (Ed.), The Chemistry of Cements, vol. 1, Academic Press, London, 1964, pp. 417-432.

[7] G. L. Kalousek, High-temperature curing of concrete under high pressure, Proceedings of the Fifth International Symposium on the Chemistry of Cement, Tokyo, Session III5, 1964, pp. 523-539.

[8] S. Chatterji, $\mathrm{CaO} / \mathrm{SiO} 2$ mole ratio of calcium silicate hydrate in fully hydrated tricalcium silicate paste, Cem. Concr. Res. 10 (6) (1980) 783-787.

[9] H. F. W. Taylor, Chemistry of cement hydration, 8th International Congress on the Chemistry of Cement, vol. 1, 1986, pp. 82-110. 
[10] H. S. Wong, N. R. Buenfeld, Monte Carlo simulation of electron-solid interactions in cement-based materials, Cem. Concr. Res. 36 (2006) 1076-1082.

[11] M. Abuhaikal, Nano-chemomechanical assessment of rice husk ash cement by wavelength dispersive spectroscopy and nanoindentation, (MSc Thesis) Massachusetts Institute of Technology, 2011.

[12] Mohammad Mahdi Ghiasi, Initial estimation of hydrate formation temperature of sweet natural gases based on new empirical correlation, Journal of Natural Gas Chemistry, Volume 21, Issue 5, September 2012, Pages 508-512.

[13] J. M. Sánchez, M. Maroño, D. Cillero, L. Montenegro, E. Ruiz, Laboratory- and bench-scale studies of a sweet watergas-shift catalyst for $\mathrm{H}_{2}$ and $\mathrm{CO}_{2}$ production in precombustion $\mathrm{CO}_{2}$ capture, Fuel, Volume 114, December 2013, Pages 191-198.

[14] Leila Aliouane, Sid-Ali Ouadfeul, Sweet Spots Discrimination in Shale Gas Reservoirs Using Seismic and Well-logs Data. A Case Study from the Worth Basin in the Barnett Shale,Energy Procedia, Volume 59, 2014, Pages 22-27

[15] Vasileios Pothakos, Clarice Nyambi, Bao-Yu Zhang, Antonios Papastergiadis, Bruno De Meulenaer, Frank Devlieghere, Spoilage potential of psychrotrophic lactic acid bacteria (LAB) species: Leuconostoc gelidum subsp. gasicomitatum and Lactococcus piscium, on sweet bell pepper (SBP) simulation medium under different gas compositions. International Journal of Food Microbiology, Volume 178, 16 May 2014, Pages 120-129

[16] Chunfang Cai, Wenxian He, Lei Jiang, Kaikai Li, Lei Xiang, Lianqi Jia Petrological and geochemical constraints on porosity difference between Lower Triassic sour- and sweetgas carbonate reservoirs in the Sichuan Basin,Marine and Petroleum Geology, Volume 56, September 2014, Pages 34-50

[17] Azad Jarrahian, Ehsan Heidaryan, A new cubic equation of state for sweet and sour natural gases even when composition is unknown. Fuel, Volume 134, 15 October 2014, Pages 333342 .

[18] Di Cai, Zhen Chang, Lili Gao, Changjing Chen, Yuanpu Niu, Peiyong Qin, Zheng Wang, Tianwei Tan. Acetone-butanolethanol (ABE) fermentation integrated with simplified gas stripping using sweet sorghum bagasse as immobilized carrier. Chemical Engineering Journal, Volume 277, 1 October 2015, Pages 176-185

[19] L. Carlos, G. Isabel, B. Irene, D. Luis I., R. Luis M. Experimental study of $\mathrm{SO} 2$ and NOx emissions in fluidized bed oxy-fuel combustion. Fuel Process Techno., 2013; 106: 587-594.

[20] M. de las Obras-Loscertales, A. Rufas, L. F. de Diego, F. García-Labiano, P. Gayán, A. Abad, J. Adánez, Effects of Temperature and Flue Gas Recycle on the $\mathrm{SO}_{2}$ and $\mathrm{NO}_{x}$ Emissions in an Oxy-fuel Fluidized Bed Combustor, Energy Procedia., 2013; 37: 1275-1282.

[21] W. Kaewboonsong, V. I. Kuprianov, N. Chovichien, Minimizing fuel and environmental costs for a variable-load power plant (co-)firing fuel oil and natural gas: Part 1 . Modeling of gaseous emissions from boiler units, Fuel Processing Technology, 2006; 87: 1085-1094

[22] A. Irabien, Environmental and economic evaluation of $\mathrm{SO}_{2}$ recovery in a ceramic hollow fibre membrane contactor. Chem Eng Process: Process Inten., 2012; 52: 151-154. 